\title{
Curriculum for Postgraduate Medicine in Bhutan's only medical university: time for need-based curricula, review, development and implementation
}

\author{
Tenzin, $K^{1}{ }^{1}$, Tenzin, $T^{1}{ }^{1}$ Dorji, $T^{2}{ }^{2}$, Tshering, K.P. ${ }^{3}$
}

\begin{abstract}
Background: The establishment of a Medical University heralded a new era of medical education in Bhutan. Four years after the Faculty of Postgraduate Medicine began giving Doctorate of Medicine courses, an urgent need was felt to revise the curricula to reflect the changing needs.
\end{abstract}

Methods: The old curricula were reviewed and revised with adoption of current trends and guidelines on medical education. The Faculty of Postgraduate Medicine conducted a series of activities and consultations with local and international experts to design curricula that would deliver to the current and future needs of the Bhutanese health system and the global shortage of the health workforce.

Results: Curricula in all the fields of postgraduate trainings were revised with adoption of well-defined learning objectives with constructive alignment of these objectives including appropriate teachinglearning strategies and appropriate assessment methods. The new curricula focuses on competency based medical education with a strong emphasis on workplace based assessments. The curricula also includes a medical humanities course and teaching methods.

Discussion: The new curricula were revised to reflect standards on par with medical institutes in the region. The curricula are implemented from 2018 onwards. Challenges are expected in its implementation in our context where medical education is at a nascent stage.

Conclusion: The revised curriculum is expected to deliver to the current and future needs and raise the standard of postgraduate medical education.

Key words: competency-based medical education; constructive alignment; curricula, learning domains; medical humanities; quality improvement.

\section{Introduction}

When modern medicine began in Bhutan in 1956, there were severe constraints in infrastructure, funding and human resources (Dorji \& Melgaard, 2012).

${ }^{1}$ Faculty of Postgraduate Medicine, Khesar Gyalpo University of Medical Sciences of Bhutan, Thimphu

${ }^{2}$ Kidu Medical Unit, His Majesty's Peoples' Project, Thimphu

${ }^{3}$ Office of the President, Khesar Gyalpo University of Medical Sciences of Bhutan, Thimphu

Corresponding Author:

Dr. Karma Tenzin

Faculty of Postgraduate Medicine, Khesar Gyalpo University of Medical Sciences of Bhutan, Thimphu

E mail: karmatenzin9@gmail.com

DOI: http://doi.org/10.4038/seajme.v12i2.46
In order to mitigate shortcomings in health human resources, the Health School was established in 1974 to train nurses and community health workers. It later expanded into the Royal Institute of Health Sciences in 1989 to provide training for various other categories of health workers such as technicians and public health professionals who went on to build a strong and unique healthcare system in Bhutan (Thinley et al., 2017; $\mathrm{MOH}, 2018$; Yangchen et al., 2017).

The most serious concern was and still remains the shortage of doctors and specialist doctors. To address this concern, the Khesar Gyalpo University of Medical Sciences was established in 2014. The Faculty of Postgraduate Medicine began as the 
Postgraduate Medical Education Center providing postgraduate training in General Surgery, Ophthalmology, Anesthesiology, Pediatrics and Obstetrics and Gynaecology in July 2014 and Internal Medicine in July 2015. The curricula were developed by a team of local experts and according to the Bhutan Medical and Health Council's "Postgraduate Medical Education Regulations 2014" (Faculty of Postgraduate Medicine, 2016).

The existing curricula were 4 years old and was being challenged by the increasing need to transform medical education to meet the evolving and specific health needs of the communities and localities. One important need was the "adoption of competency-based curricula that [were] responsive to the changing needs" (Kiguli-Malwadde et al., 2014).

The existing postgraduate curricula comprised of goals, learning objectives and outcomes, core competencies, teaching-learning methods and assessment methods (PGMEC, 2014). Historically, medical education curricula predominantly emphasized on the cognitive domain and placed too much emphasis on whether students and trainees passed the exams and insufficient emphasis on their performance as clinicians. There was a call for designing separate objectives for cognitive, psychomotor and affective domains of learning (Anderson \& Krathwohl, 2001; Adhikari, 2016).

The Faculty of Postgraduate Medicine adopted a number of initiatives to train the teaching faculties to align their teaching methods with the current trends of medical education and assessment methods. Upon the assessment of the quality of medical education and assessment methods, it was realized that the existing curricula emphasized on knowledge based learning and not on the acquisition of skills and competency and the development of the affective domain (Tenzin et al., 2016; Tenzin et al., 2017). Therefore, it was recognized that there was an urgent need to revisit the existing curricula and frame clearly defined objectives for the cognitive, psychomotor and the affective domains of learning. In addition, major revision of curricula is recommended by all the educational authorities every 5 years as more than $50 \%$ of all medical knowledge becomes outdated within this period (Olopade et al., 2016). Therefore, in October 2017, the Faculty of Postgraduate Medicine constituted a Curriculum Committee and started a ninemonth process to revise eight existing postgraduate curricula and develop three new curricula in Psychiatry, Otorhinolaryngology and Emergency Medicine.

\section{Methods}

This paper is a document of a series of overlapping processes that took place from 2016 through 2018 to revise and develop postgraduate curricula (Figure 01). This project took an academic approach with approval from the University and also ethics approval from the Research Ethics Board of Health, Ministry of Health (via approval no $\mathrm{REBH} / \mathrm{PO} / 2018 / 048$ dated 19 July 2018).

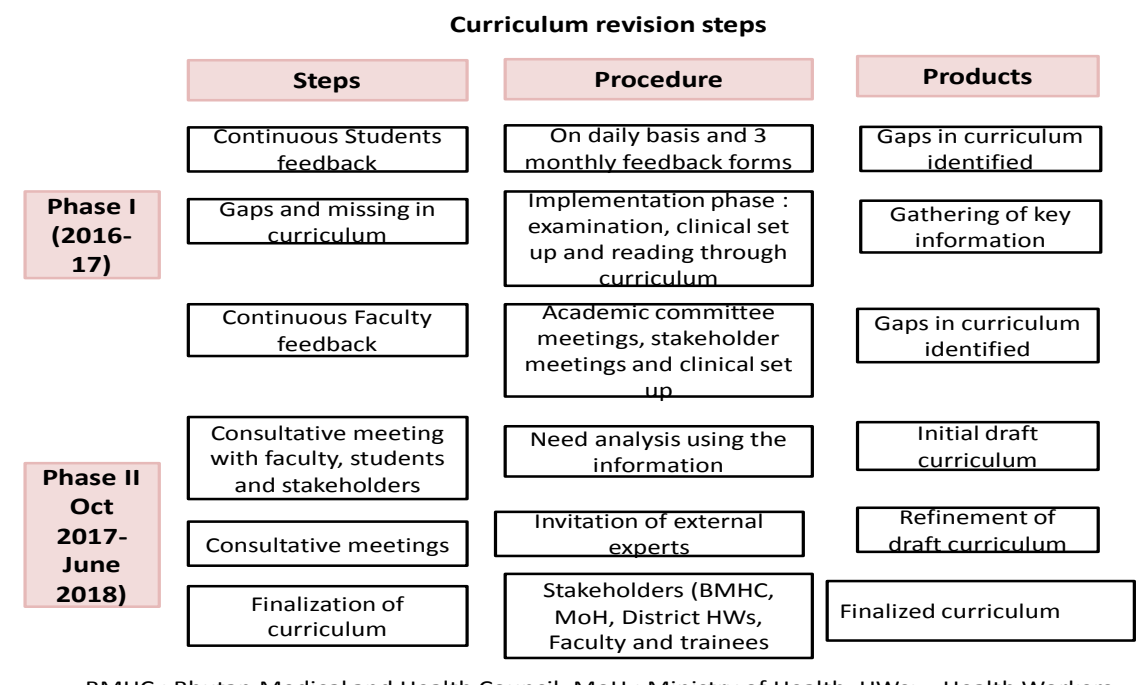

BMHC : Bhutan Medical and Health Council; MoH : Ministry of Health; HWs: = Health Workers

Figure 1: Summary of steps in curriculum revision at the Faculty of Postgraduate Medicine, Khesar Gyalpo University of Medical Sciences of Bhutan, 2016-2018 
Preparatory process for curriculum review

Step one: Need assessment for revision of existing Postgraduate curriculum

The need for revision of the existing curricula was deliberated from 2016-2017 at various forums such as Postgraduate Board of Management, Academic Committee, coordination meetings, feedback from faculty
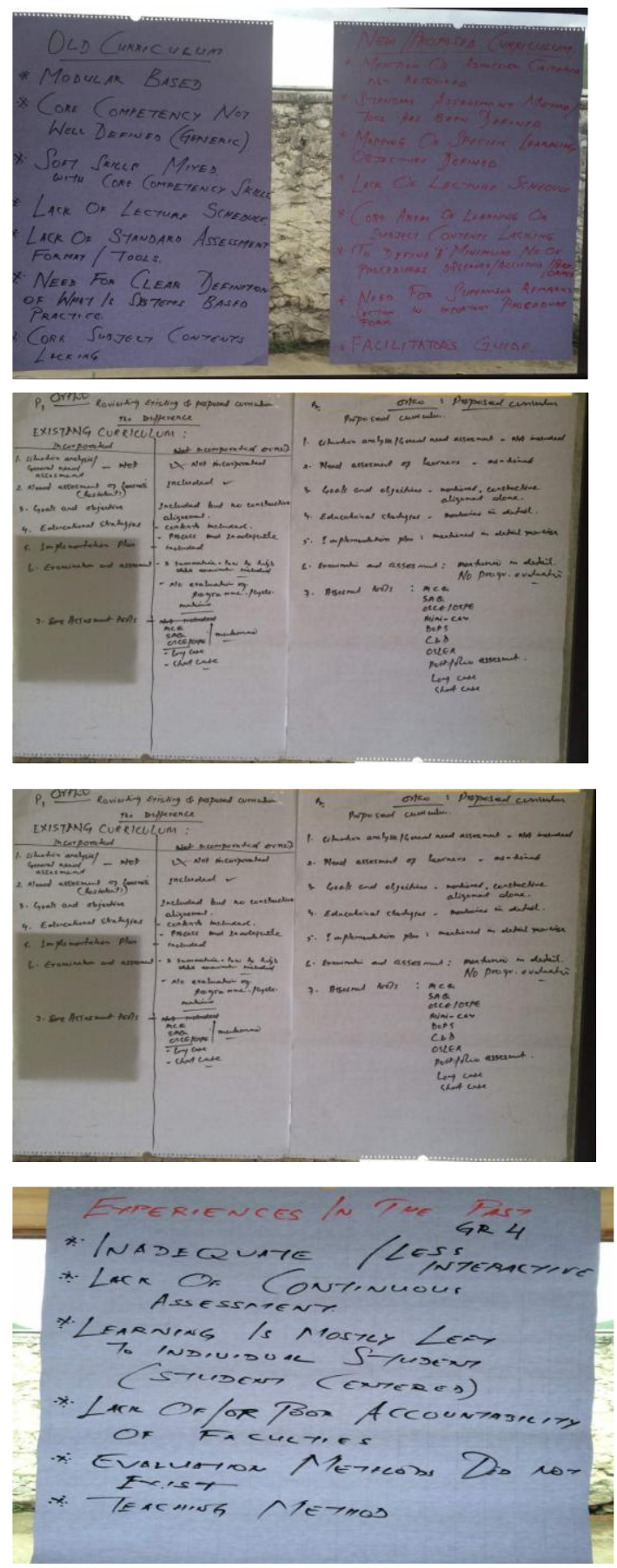

members, students and external examiners. Feedback was also collected from the district health workers, academic administrators and members from Bhutan Medical and Health Council from March-May 2018 (a summary shown in Figures 1 to 3 ). In addition, deliberations were also held with curriculum experts from the B.P.K. Institute of Health Sciences, Nepal and G.S. Medical College, Mumbai in February-May 2018.
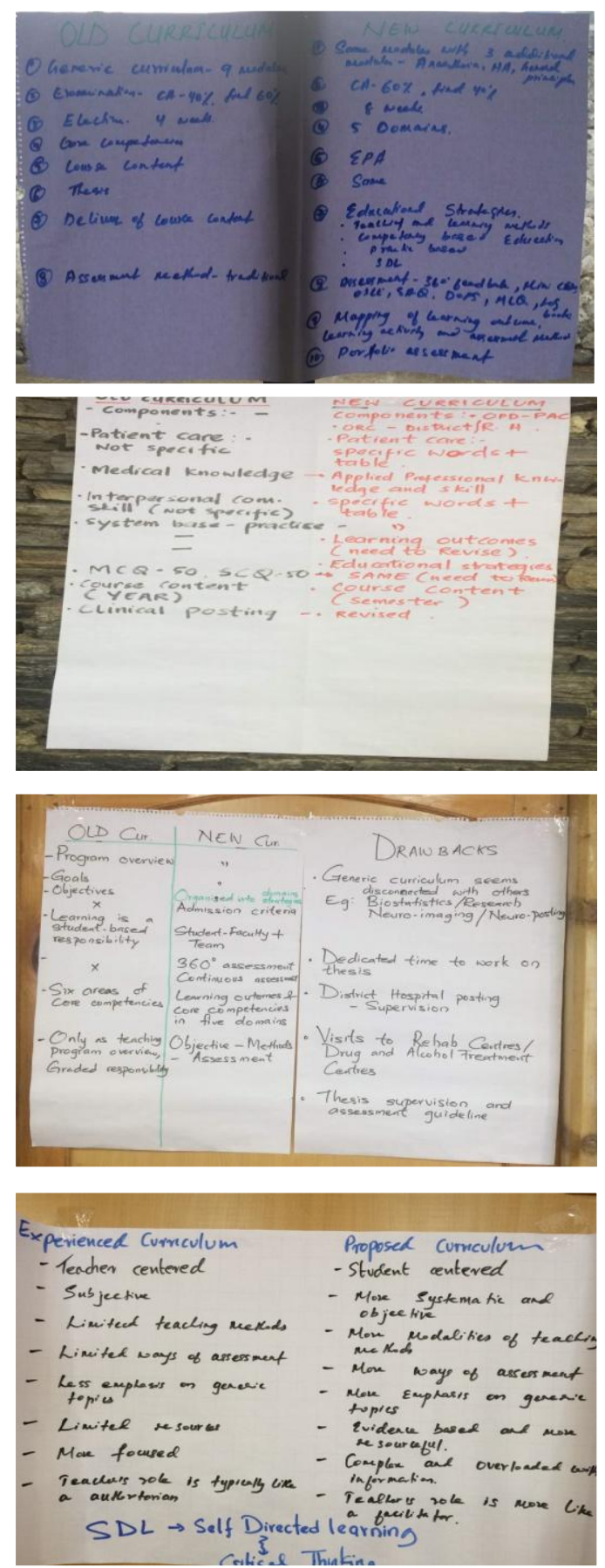

Figure 2: Presentation by stakeholders on the existing and proposed postgraduate curricula, Faculty of Postgraduate Medicine, Khesar Gyalpo University of Medical Sciences of Bhutan, 2018 

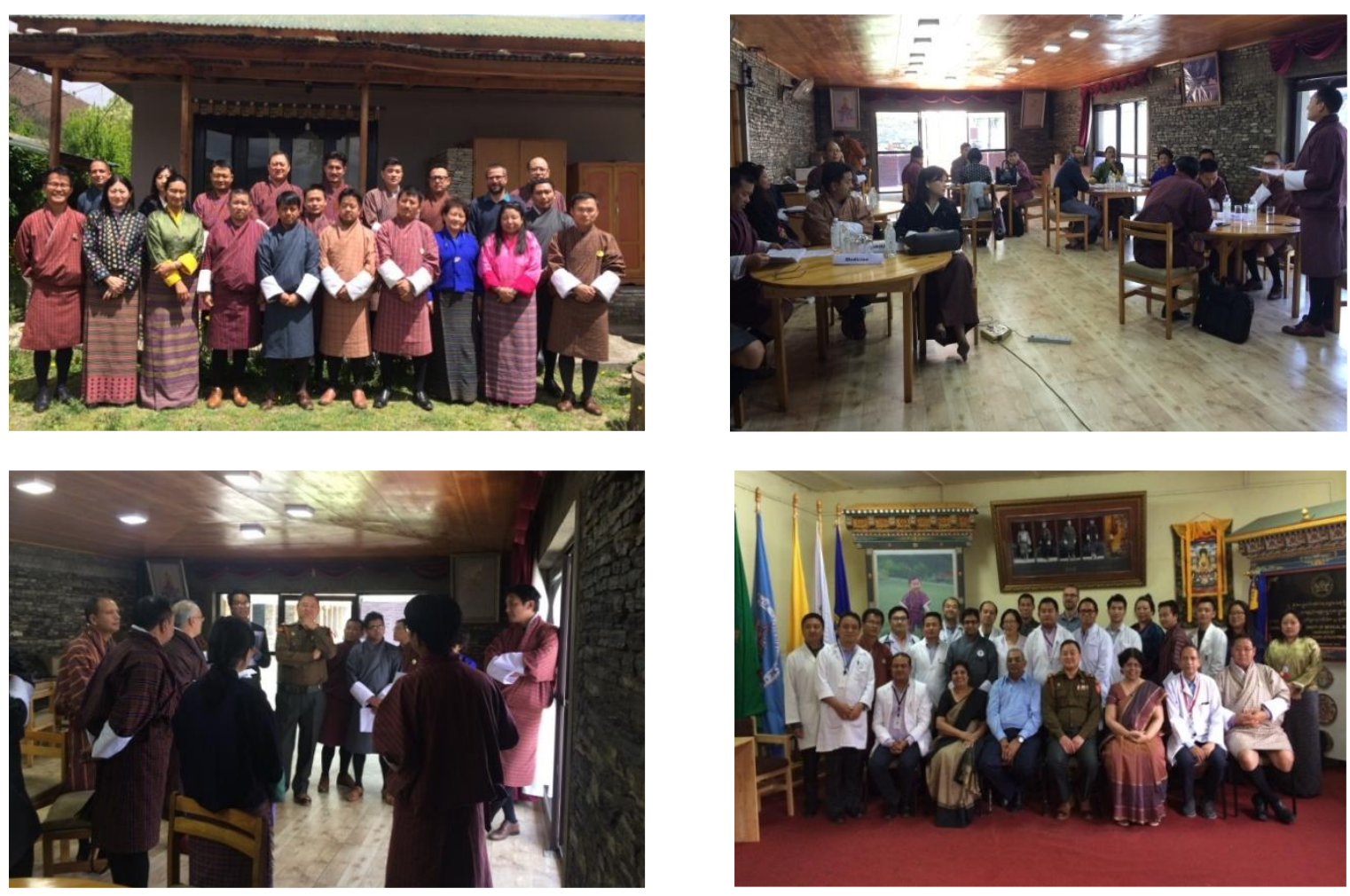

Figure 3: Stakeholders involved in curriculum review including curriculum committee

\section{Step two: Capacity development of the faculty members}

Nearly all teaching faculty were provided workshops on pedagogy, advance student assessment, teaching-learning strategies and curriculum development from July 2016December 2017 with experts from BP Koirala Institute of Health Sciences, Dharan, Nepal; Ludwig Maximilian University (LMU), Germany; and GS Medical College, Mumbai, India.

\section{Step three: Formation of the Curriculum} Committee

As mandated by the university regulations, a Curriculum Committee constituting of course coordinators, medical education coordinator with Dean as chairperson was constituted in November 2017.

\section{Results}

Reforming the curriculum (October 2017-June 2018)

The course coordinators led the discussion at their respective departments. The faculty members in each department identified skills or knowledge that were missing from the old curriculum and changes were made accordingly to produce draft zero. The curriculum committee then reviewed the draft through online and face to face consultations rating them against national and international curriculum education guidelines to produce draft one (Kern et al., 1998; CanMEDS, 2015; RACGP. 2016). The focus of this phase was the assessment of the strengths and weakness of the existing curriculum, as shown in Table 1.

The "draft one" was deliberated on many occasions both online and on face-to-face consultative meetings with all the stakeholders from February to May 2018. This rigorous exercise produced "draft seven" of the curriculum by end of May 2018. Regional experts from B.P.K. Institute of Health Sciences, Nepal and G.S. Medical College, India provided their expert input into the drafts of the curricula.

\section{Improvement of Objectives}

The objectives were ill defined or almost nonexistant in the old curricula. The revision process resulted in well-defined objectives in three domains of learning pertinent to changing roles of clinicians (Anderson \& Krathwohl, 2001). 
Table 1: Strengths and weaknesses in "old" curriculum for Doctorate of Medicine (MD) at the Faculty of Postgraduate Medicine, Khesar Gyalpo University of Medical Sciences of Bhutan, 2018

\section{Strengths}

- Curriculum was largely adopted from regional institutes giving good experiences in medical education.

- Faculty members consisted of experienced, well-balanced, and equally weighted teaching staffs for carrying out the changes required by the new curriculum.

- Joint instruction of all students promoting excellence, especially in generic topics

- Tradition of joint session in many of the clinical departments form the vestiges of integration.

- Established culture of proper teaching and assessment methods

- Establishment faculty development program, which actually acted as a springboard for new curriculum.

- Strong support from management for the academics and new curriculum.

Deficiencies

- Lack of integration of the basic medical science subjects, thus leading to disjointed learning.

- Abstract teaching of core medical science subjects without much appreciation of clinical importance.

- Students have minimal opportunity for self-directed learning and critical thinking skills.

- Curriculum has minimal or no room for opportunity for face to face interaction between faculty and student

- Curriculum does not give much emphasis on the affective domain development of student

- Lack of opportunity for students to get assessed on regular basis.

- Lack of opportunity to do more community based learning

- Lack of competency-based learning

Contents of the Foundation Course

In the old curriculum, the "Foundation Course" was given in nine modules during the first six months of the postgraduate training. During the revision, the contents of these modules were defined and re-structured.

\section{Introduction of new components in new curricula}

The 'medical humanities course' was introduced aiming to orient the postgraduate trainees to the principles of medical ethics, health systems and professionalism. In the 'Resident as a Teacher' course, the trainees learn the basics of teaching-learning methods. To allow innovative ideas to benefit of the patients and the teaching hospital, every trainee is given an opportunity to implement at least one 'Quality Improvement Project'.

\section{Development of competency based curricula}

To ensure that the new curricula were competency-based, the learning objectives were grouped into broad domains of competencies which were then aligned with the teaching methods and the appropriate assessment tools (constructive alignment).

\section{Determination of desired core competencies}

The core competencies described in the old curricula were adopted from Accreditation Council of Graduate Medical Education guidelines (ACGME, 2018). In the new curricula, these core competencies were redefined and aligned with the objectives, teaching-learning methods and appropriate assessment methods. The core competencies that are addressed by the new curriculum are: (1) Medical knowledge and patient care; (2) Interpersonal and communication skills; (3) Professionalism and ethics; (4) Practice-based learning and improvement; and (5) Systembased practice.

\section{Modifications to the assessment methods}

The current trends in medical education focuses on gathering evidence of clinical competence and appropriate behaviour observed in the clinical environment. In the Miller's pyramid for assessing clinical competence, workplace-based method of collecting information about doctors' performance in their everyday practice at work environment is the highest level (Norcini, 2003; Liu, 2012; Ramani \& Leinster, 2008). 
One of the major improvements in the new curriculum is the adoption of 'work-place based assessment (WBPA)' (Liu, 2012). This assessment is performed as a Continuous Assessment contributing to a total of $20 \%$ of the total marks (Table 2).

a. The Continuous Assessment (Work-place Based Assessment) includes Mini Clinical Evaluation Exercise (mini-CEX), Direct Observation of Procedural Skill (DOPS), 360 Degree Feedback, Case-based Discussion (CBD), Logbook and Portfolio (Liu, 2012). b. The Summative Assessment is divided into two components. For the assessment of knowledge component, multiple-choice questions (MCQs), short answer questions (SAQs), and structured long essay question (SLEQs) are adopted. For the assessment of clinical skills, short case, long case through use of objective structured long examination records (OSLERs) and objective structured clinical examinations (OSCEs) are adopted (Steinert et al., 2006). The summative assessments are conducted as the Faculty's Institute Examination I (10\%), II $(20 \%)$ and III (30\%), thesis defence $(20 \%)$.

Table 2: Summary of assessment methods in new postgraduate curricula, Faculty of Postgraduate Medicine, Khesar Gyalpo University of Medical Sciences of Bhutan, 2018

\begin{tabular}{|c|c|c|c|c|c|}
\hline \multirow{2}{*}{ Semester } & \multirow{2}{*}{ Examinations } & \multicolumn{2}{|c|}{ Components } & \multirow{2}{*}{$\begin{array}{l}\text { Total } \\
\text { marks }\end{array}$} & \multirow{2}{*}{ Weightage (\%) } \\
\hline & & Written & Practical & & \\
\hline \multirow{2}{*}{$\begin{array}{l}\text { Semester } \\
1-2\end{array}$} & $\begin{array}{l}\text { Continuous } \\
\text { assessment }\end{array}$ & $\begin{array}{l}\text { Mini-Cex, DOPS, } \\
\text { book/portfolio }\end{array}$ & 360 degree feedback, log & 100 & \multirow{2}{*}{$\begin{array}{l}\text { Continuous marks }=5 \\
\text { Term Exams }=10\end{array}$} \\
\hline & $\begin{array}{l}\text { Institute } \\
\text { Examination I }\end{array}$ & $\begin{array}{l}\text { Paper I - V } \\
\text { 1. MCQ: } 50 \% \\
\text { 2. SAQ/SLEQs: } \\
50 \%\end{array}$ & $\begin{array}{l}\text { OSPE: } 20 \text { stations } 5 \text { marks } \\
\text { each }\end{array}$ & 200 & \\
\hline \multirow[b]{2}{*}{$\begin{array}{l}\text { Semester } \\
3-4\end{array}$} & $\begin{array}{l}\text { Continuous } \\
\text { assessment }\end{array}$ & $\begin{array}{l}\text { Mini-Cex, DOPS, } \\
\text { feedback, log boc }\end{array}$ & OSLER, 360 degree & 100 & \multirow[b]{2}{*}{$\begin{array}{l}\text { Continuous marks }=5 \\
\text { Term Exams }=20\end{array}$} \\
\hline & $\begin{array}{l}\text { Institute } \\
\text { Examination II }\end{array}$ & $\begin{array}{l}\text { Paper I - II } \\
\text { 1. MCQ: } 50 \% \\
\text { 2. SAQ/SLEQs: } \\
50 \text { marks }\end{array}$ & $\begin{array}{l}\text { 1. OSCE, } 10 \text { stations } 100 \\
\text { marks } \\
\text { 2. Two short cases: } 50 \text { marks } \\
\text { each } \\
\text { 3. One OSLER: } 100 \text { marks }\end{array}$ & 400 & \\
\hline \multirow{2}{*}{$\begin{array}{l}\text { Semester } \\
5-6\end{array}$} & $\begin{array}{l}\text { Continuous } \\
\text { assessment }\end{array}$ & $\begin{array}{l}\text { Mini-Cex, DOPS, } \\
\text { feedback, log boc }\end{array}$ & $\begin{array}{l}\text {, OSLER, } 360 \text { degree } \\
\text { ortfolio }\end{array}$ & 100 & \multirow{2}{*}{$\begin{array}{l}\text { Continuous marks }=5 \\
\text { Thesis }=20\end{array}$} \\
\hline & $\begin{array}{l}\text { Submission of } \\
\text { Thesis }\end{array}$ & $\begin{array}{l}\text { 1. Thesis conten } \\
\text { 2. Oral/viva voce }\end{array}$ & $\begin{array}{l}\text { presentation: } 25 \text { marks } \\
\text { marks }\end{array}$ & 100 & \\
\hline \multirow[b]{2}{*}{$\begin{array}{l}\text { Semester } \\
7-8\end{array}$} & $\begin{array}{l}\text { Continuous } \\
\text { assessment }\end{array}$ & $\begin{array}{l}\text { Mini-Cex, DOPS, } \\
\text { feedback, log boc }\end{array}$ & $\begin{array}{l}\text {, OSLER, } 360 \text { degree } \\
\text { rtfolio }\end{array}$ & 100 & \multirow[b]{2}{*}{$\begin{array}{l}\text { Continuous marks }=5 \\
\text { Term Exams }=30\end{array}$} \\
\hline & $\begin{array}{l}\text { Institute } \\
\text { Examination III }\end{array}$ & $\begin{array}{l}\text { Paper I - II } \\
\text { 1. } \text { MCQ: } 50 \% \\
\text { 2. SAQ/SLEQs: } \\
50 \%\end{array}$ & $\begin{array}{l}\text { 1. OSCE, } 10 \text { stations } 100 \\
\text { marks } \\
\text { 2. Two short case: } 50 \text { marks } \\
\text { each } \\
\text { 3. One OSLER: } 100 \text { marks }\end{array}$ & 700 & \\
\hline
\end{tabular}

${ }^{*} C B D$ - case based discussion, DOPS - direct observation of procedure, MCQ - Multiple choice question, OSCE - Objective structured clinical examination, OSPE - objective structured practical examination, OSLER objective structured long examination record, SAQ - short answer question, SLEQ - structured long essay question 
Implementation and Strategies to overcome challenges

New teaching strategies such as case-based learning, self-directed learning, use of information communication technology, clinical audits and research are included to translate the learning objectives and competency domains. These methods were integrated with traditional methods such as ward teaching, lectures, journal clubs and grand rounds.

These changes required inviting the University to refocus and invest significantly on faculty development program and resulted in establishment of the Medical Education Unit at the Faculty of Postgraduate Medicine.

\section{Discussion}

The cardinal feature of the revised curricula is migration from traditional approaches in teaching learning strategies to modern and recent trends, inclusion of a medical humanities course to address the shortcomings in development of affective domains and adoption of competency-based education. A strong curriculum is imperative especially for the newly established Khesar Gyalpo University. The University revised its postgraduate curricula with objective of producing specialist doctors who can deliver both to the current and future needs of the Bhutanese health system and the global shortage of health workers. These changes were adopted from the experiences from countries that face similar challenges in medical education (Malwadde et al., 2014; Olopade et al., 2016).

In the new curriculum, the methods of instruction and assessment were chosen to suit our students and the learning environment. The workplace based assessment was added to provide an enabling environment for students to learn in their work environment and inculcate the culture of lifelong learning (Leinster, 2008; RCPath, 2018)

\section{Improving teaching capacity}

Faculty development programs were provided to equip the teaching faculty to maximally use the learning opportunities. Faculty development programs have strong influence on increase teacher self-efficacy and productivity of medical educators (Rowbotham, 2015; Steinert et al., 2006).

\section{Implementation of the new curriculum}

The new curriculum was approved and implemented in the academic session beginning with the intake of 13 postgraduate students in July 2018. The Faculty of Postgraduate Medicine foresees numerous challenges in its implementation as noted in similar settings in other countries (Badyal et al., 2014; Shankar, 2014).

The Khesar Gyalpo University has a unique challenge with $90 \%$ of teaching faculty employed as adjunct from the Jigme Dorji Wangchuck National Referral Hospital, which is an autonomous agency.

For the clinicians at the National Referral Hospital, clinical duty takes priority over teaching. The majority of the adjunct faculty graduated from postgraduate institutes in the South Asian region where they did not receive exposure to assessments methods such as workplace based assessments. This was a barrier that needed to be overcome in the initial phases of implementation of the new curricula (Shankar, 2014). The Faculty of Postgraduate Medicine has begun the process of familiarization the newer assessment tools through the development of terms of references be followed by workshop on WPBA by experts from Christian Medical College, Ludhiana, India and Ludwig Maximilian University, Munich, Germany in January 2019.

Harden (2007) describes the problems associated in implementation of new curriculum. The nine dimensions used to determine the implementation 'score' include: learning outcomes, communication with staff and students, educational strategies, course content, student progression, assessment, educational environment and student selection Harden, (2007). Therefore, the University has developed plans to provide more training opportunity for the faculty members with invitation of experts in competency-based medical education in 2019.

\section{Conclusion}

The postgraduate curricula at the Khesar Gyalpo University of Medical Sciences of Bhutan was revised into a competency based curricula that is aimed at delivering graduates who are prepared to answer the current and future needs of the Bhutanese health system. The most recent trends and internationally accepted review processes were utilized in 
revising the curricula raising the standard of postgraduate medical education in Bhutan.

\section{Acknowledgement}

The authors would like to express deepest gratitude to Dr. Chabi Lal Adhikari, General Practice Physician for permitting to refer and use the GP curriculum as model during the entire process of curriculum development. Dr. A. Supe, Dr. Nirmala Rege, Dr. Jyotsna Rimal and Prof. Dr. S. Matthias all played pivotal roles.

We would also like to express our gratitude to the Office of the President, Khesar Gyalpo University of Medical Sciences of Bhutan and faculty members for support and contributions.

\section{References}

ACGME (2018) Accreditation Council of Graduate Medical Education guidelines.

Adhikari, L.C. (2016) Curriculum for Masters in General Practice. First edition. Khesar Gyalpo University of Medical Sciences of Bhutan, Thimphu, Bhutan.

Anderson, L.W. \& Krathwohl, D.R. (2001) A taxonomy for learning, teaching, and assessing. A bridged edition. Boston, MA: Allyn and Bacon.

Badyal, D.K., Desai, C., Tripathi, S.K., Dhaneria, S.P., Chandy, S.J. \& Bezbaruah, B.K. (2014) Postgraduate pharmacology curriculum in medical institutions in India: Time for needbased appraisal and modifications, Indian Journal of Pharmacology, 46, 6, pp. 584-589.

CanMEDS. (2015) Better standards, better physicians, better care. The Royal college of Physicians and Surgeons of Canada. Available at:http://www.royalcollege.ca/rcsite/canmeds/ca nmeds-frameworks-e

Dorji, T. \& Melgaard, B. (2012) Medical History of Bhutan: Chronicle of Health and Disease from Bon Times to Today. Thimphu, Bhutan: Centre for Research Initiatives. Thimphu, Bhutan.

FoPGM (2016) Postgraduate residency regulations 2016. Faculty of Postgraduate Medicine, Khesar Gyalpo University of Medical Sciences of Bhutan. Thimphu, Bhutan.

Harden, R.M. (2007) Outcome-based education-the ostrich, the peacock and the beaver, Medical Teacher, 29, pp. 666-671.

Kern, D., Thomas, P., Howard, D. \& Bass, E. (1998) Curriculum development for medical education: a six-step approach. Baltimore and London: The Johns Hopkins University Press., USA.
Liu, C. (2012) An introduction to workplace-based assessments, Gastroenterology and Hepatology from Bed to Bench, 5, 1, pp. 24-28.

Leinster, S.J. (2003) Medical education in the real world, Medical Education, 37, 5, 00. 397-8

Kiguli-Malwadde, E., Olapade-Olaopa, E.O., Kiguli, S., Chen, C., Sewankambo, N.K., Ogunniyi, A.O., Mukwaya, S. \& Omaswa, F. (2014) Competency-based medical education in two Sub-Saharan African medical schools, Advances in Medical Education and Practice, 5, pp. 482-489.

MOH (2018) Annual Health Bulletin 2018. Ministry of Health, Royal Government of Bhutan, Thimphu, Bhutan.

Norcini, J.J. (2003) ABC of learning and teaching in medicine: Work based assessment, BMJ: British Medical Journal, 326, 7392, pp. 753755.

Olopade, F.E., Adaramoye, O.A., Raji, Y., Fasola, A.O. \& Olapade-Olaopa, E.O. (2016) Developing a competency-based medical education curriculum for the core basic medical sciences in an African Medical School, Advances in Medical Education and Practice, 7, pp. 389-398.

PGMEC (2014) Curriculum for MD Residency Programme in Paediatrics. First edition. Khesar Gyalpo University of Medical Sciences of Bhutan, Thimphu, Bhutan.

RACGP (2016) Curriculum for Australian General Practice 2016. Available at: http://www.racgp.org.au/education/curriculum/2 016-curriculum/the-five-domains-of-generalpractice.

Ramani, S. \& Leinster, S. (2008) AMEE Guide no 34: Teaching in the clinical environment, Medical Teacher, 30, 4, pp. 347-364.

RCPath (2018) Definitions-Workplace-Based Assessment. Royal College of Pathologists. ASM, 2, pp. 1-2.

Rowbotham, M.A. (2015) The impact of faculty development on teacher self-efficacy, skills and retention. Edwardsville, IL: Illinois Education Research Council at Southern Illinois University Edwardsville.

Shankar, P.R. (2014) Challenges in Implementing an Integrated Curriculum in Xavier University School of Medicine, Aruba, Education in Medicine Journal, 6, 4, pp. 74-77.

Steinert, Y., Mann, K., Centeno, A., Dolmans, D. Spencer, J., Gelula, M. \& Prideaux, D. (2006) A systematic review of faculty development initiatives designed to improve teaching effectiveness in medical education: BEME Guide No. 8. Medical Teacher, 28, 6, pp. 497526. 
Tenzin, K., Dorji, T. \& Tenzin, T. (2017) Construction of Multiple Choice Questions before and After an Educational Intervention, Journal of the Nepal Medical Association, 56, 205, pp. 112-116.

Tenzin, K., Pem, D. \& Gyeltshen, T. (2016) Perception of students on the teaching methodologies utilized at Khesar Gyalpo University of Medical Sciences of Bhutan, Bhutan Health Journal, 2, 2, pp. 10-15.
Thinley, S., Tshering, P., Wangmo, K., Wangchuk, N., Dorji, T., Tobgay, T. \& Sharma, J. (2017) The Kingdom of Bhutan: Health System Review. Health Systems in Transition. Asia Pacific Observatory on Health Systems and Policies, pp. 7.

Yangchen, S., Tobgay, T. \& Melgaard B. (2017) Bhutanese Health and the Health Care System: Past, Present, and Future, Druk Journal, 2, 1 Available at: http://drukjournal.bt/bhutanesehealth-and-the-health-care-system-pastpresent-and-future/ 